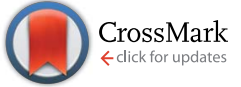

Cite this: Chem. Sci., 2015, 6, 6091

Received 17th June 2015

Accepted 20th July 2015

DOI: $10.1039 / \mathrm{c} 5 \mathrm{sc} 02153 \mathrm{~g}$

www.rsc.org/chemicalscience

\title{
Dielectric-dependent electron transfer behaviour of cobalt hexacyanides in a solid solution of sodium chloride
}

\author{
Di Huang, Yiliang Zhu, Ya-Qiong Su, Jie Zhang, Lianhuan Han, De-Yin Wu, \\ Zhong-Qun Tian and Dongping Zhan*
}

\begin{abstract}
Here we emphasise the importance of the dielectric environment on the electron transfer behavior in interfacial electrochemical systems. Through doping cobalt hexacyanide $\left(\mathrm{Co}(\mathrm{CN})_{6}{ }^{3-}\right)$ into single microcrystals of sodium chloride $(\mathrm{NaCl})$, for the first time, we obtained the direct electrochemical behavior of $\mathrm{Co}(\mathrm{CN})_{6}{ }^{3-}$ which is hardly ever obtained in either aqueous or conventional nonaqueous solutions. DFT calculations elucidate that, as the $\mathrm{Co}(\mathrm{CN})_{6}{ }^{3-}$ anions occupy the lattice units of $\mathrm{NaCl}_{6}{ }^{5-}$ in the $\mathrm{NaCl}$ microcrystal, the redox energy barrier of $\mathrm{Co}(\mathrm{CN})_{6}{ }^{3-14-}$ is decreased dramatically due to the low dielectric constant of $\mathrm{NaCl}$. Meanwhile, the low-spin $\mathrm{Co}(\mathrm{CN})_{6}{ }^{4-}$ anions are stabilized in the lattices of the $\mathrm{NaCl}$ microcrystal. The results also show that the $\mathrm{NaCl}$ microcrystal is a potential solvent for solidstate electrochemistry at ambient temperature.
\end{abstract}

\section{Introduction}

The dielectric property of solvents, crucial in interfacial electron transfer reactions, has been paid little attention in the initiative design of electrochemical systems. In principle, the hexacyanides of transition metals have a good capability of electron transfer due to both the multivalent central cations and the homogeneous charge distribution. For example, potassium ferricyanide $\left(\mathrm{K}_{3} \mathrm{Fe}(\mathrm{CN})_{6}\right)$, where the standard electrode potential of the $\mathrm{Fe}(\mathrm{CN})_{6}{ }^{3-/ 4-}$ couple is $0.361 \mathrm{~V}$ versus the normal hydrogen electrode (NHE) at $25{ }^{\circ} \mathrm{C}$, is used widely as a classic redox couple in electrochemistry. ${ }^{1}$ The reversible electron transfer behavior underlies the determination of the effective area of the glassy carbon electrodes. ${ }^{2}$ However, despite the similar molecular structure of cobalt hexacyanide $\left(\mathrm{Co}(\mathrm{CN})_{6}{ }^{3-}\right)$ to $\mathrm{Fe}(\mathrm{CN})_{6}{ }^{3-}$, redox behavior of $\mathrm{Co}(\mathrm{CN})_{6}{ }^{3-}$ in conventional aqueous or nonaqueous solutions has been seldom reported to date. Although theoretical calculation implies the possibility of the dielectric constant of the electrolyte solution to be decreased to 5 , this indication has never been validated experimentally due to the lack of a qualified solvent. ${ }^{3}$ Since the dielectric constant of $\mathrm{NaCl}\left(\varepsilon: 6.0 \mathrm{~F} \mathrm{~m}^{-1}\right)$ is very close to $5 \mathrm{~F} \mathrm{~m}^{-1}$, based on our previous research on solid solutions of $\mathrm{NaCl}$ microcrystals, ${ }^{4}$ we synthesize $\mathrm{Co}(\mathrm{CN})_{6}{ }^{3-}$ doped $\mathrm{NaCl}$ microcrystals and observed the direct electrochemical behavior of $\mathrm{Co}(\mathrm{CN})_{6}{ }^{3-/ 4-}$ in the dielectric environment of the $\mathrm{NaCl}$ microcrystal.

State Key Laboratory of Physical Chemistry of Solid Surfaces, Department of Chemistry, College of Chemistry and Chemical Engineering, Xiamen University, 422 Siming South Road, Xiamen 361005, China.E-mail:dpzhan@xmu.edu.cn
We have developed a scanning electrochemical cell microscopy (SECCM) method to culture the $\mathrm{NaCl}$ solid-solution microcrystals, wherein the redox couples are doped as solute. ${ }^{4}$ Derived from scanning electrochemical microscopy, SECCM employs a micropipette with a micro- or nano-meter sized orifice as both the scanning tip and the electrochemical cell (Fig. 1) $;^{5}$ it has been proved as an effective technique in various research areas including in reaction kinetics, ${ }^{6}$ micro- or nanopatterning and imaging, ${ }^{5,, 7}$ local corrosion or deposition, ${ }^{8}$ and also in catalyst screening. ${ }^{9}$ It was found that the $\mathrm{Fe}(\mathrm{CN})_{6}{ }^{3-/ 4-}$ / $\mathrm{NaCl}$ solid-solution microcrystals have excellent solid-state redox behaviors in the absence of any liquid electrolyte, because the doped redox couple makes them electronic conductors while the crystal defects make them ionic conductors. ${ }^{\boldsymbol{a}, \boldsymbol{b}}$ Here, for the first time, we report the dielectric environment dependent, direct electron transfer behavior of $\mathrm{Co}(\mathrm{CN})_{6}{ }^{3-/ 4-}$ in $\mathrm{NaCl}$ microcrystals.

\section{Experimental section}

Chemicals, materials, and instruments

$\mathrm{NaCl}$ and $\mathrm{Na}_{3} \mathrm{Co}(\mathrm{CN})_{6}$ were of analytical grade or better (Sinopharm Co., China). All aqueous solutions were prepared with deionized water (18.2 M $\Omega$, Milli-Q, Millipore Corp.). The borosilicate micropipetts (o.d., $1.2 \mathrm{~mm}$; i.d., $0.8 \mathrm{~mm}$ ) with an orifice of 3-10 $\mu \mathrm{m}$ diameter were prepared with a programmed laser puller PS-2000 (Sutter Co., USA) as reported previously. ${ }^{4,15}$ The $\mathrm{Au}$ and $\mathrm{Pt}$ thin-film coated glass slides were prepared through magnetron sputter plating (JC500-3/D, Chengdu Vacuum Equipment Co., China). The ITO glass slides are a kind gift from Prof. Bin Ren at Xiamen University. Before experiments, the 


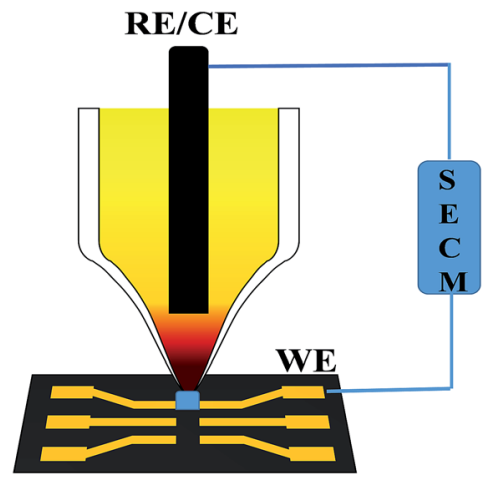

Fig. 1 Schematic diagram of the assembly of the $\mathrm{Co}(\mathrm{CN})_{6}{ }^{3-} / \mathrm{NaCl}$ microcrystals into an electrochemical chip by SECCM: a microcapillary with a micrometer-sized orifice was employed as both the scanning tip and the electrochemical cell; the reference and counter electrodes were inserted in the microcapillary, and a pair of gold microelectrodes was used on the electrochemical microchip as the working electrodes.

slides were cleaned with acetone and deionized water several times and dried with pure nitrogen gas. A scanning electron microscope (SEM, Hitachi High-Technologies Co., Japan) was employed to obtain geometric topography and elementary analysis of the single microcrystals. Confocal Raman spectrum experiments were performed with a Renishaw inVia Raman microscope (Renishaw Co., British) to confirm the composition of microcrystalline solution. All electrochemical experiments were performed with the SECM workstation CHI920c (CHI Instrument Co., USA).

\section{Culture and assembly of the $\mathrm{Na}_{3} \mathrm{Co}(\mathrm{CN})_{6} / \mathrm{NaCl}$ microcrystals}

We have developed the SECCM technique to culture and to assemble the $\mathrm{Na}_{3} \mathrm{Co}(\mathrm{CN})_{6} / \mathrm{NaCl}$ microcrystal. ${ }^{4}$ A micropipette with a micrometer sized orifice acts as both the scanning tip and the electrolytic cell. $\mathrm{An} \mathrm{Ag} / \mathrm{AgCl}$ wire was inserted into the micropipette as both the counter and reference electrodes. A conductive substrate, such as an ITO, Au, or Pt thin-film-coated glass slide, was the working electrode. With the help of the video camera, the micropipette was moved to be in contact with the conductive substrate. Since the tip and substrate were in contact with each other through a $\sim$ picoliter or $\sim$ femtoliter drop of electrolyte solution, the electrochemical reactions were confined in the small volume of the microdrop between the tip and the substrate. Actually, the spatial resolution of the SECCM depends on the size of the microdrop. When the tip was scanning, the whole electrochemical microsystem moved. Due to the evaporation of the water, the microcrystal can be obtained on the substrate. In order to form an electrochemical system, the microcrystal was assembled on the gap between a pair of gold microwires, which was deposited on a microchip made by lithography techniques.

\section{Theoretical calculations}

The quantum-chemical calculations were carried out for geometry optimizations at the density functional theory (DFT) level with the hybrid functional B3LYP by using the Gaussian 09 package. ${ }^{16}$ For the $\mathrm{C}$ and $\mathrm{N}$ atoms, the basis set used was $6-311+\mathrm{G}^{* *} \cdot{ }^{17}$ For the Co atom, the small core pseudopotential basis set LanL2DZ was adopted. ${ }^{18}$ To take the solvent effect into account, the Polarized Continuum Model (PCM) was used in all calculations. ${ }^{19}$ The dielectric constant $\varepsilon$ is $78.3 \mathrm{~F} \mathrm{~m}^{-1}$ for water as well as $6.0 \mathrm{~F} \mathrm{~m}^{-1}$ for the $\mathrm{NaCl}$ solid-solution microcrystal. The Potential Energy Curves (PES) were fitted by optimizing and obtaining some special single point energies along the reaction coordinates.

\section{Results and discussion}

As depicted in Fig. 1, the micropipette contacts with the conductive substrate through an electrolyte microdrop with a volume of pico or femto liter to construct the electrochemical microsystem. Water will evaporate since the microdrop is exposed to the atmosphere. From the Kelvin equation: ${ }^{10}$

$$
R T \ln \left(P / P_{0}\right)=2 \gamma M / \rho r
$$

The smaller the $r$ is, the higher the $P$ is, and the faster the water evaporates, where $P$ is the actual evaporation pressure, $P_{0}$ the saturated evaporation pressure, $\gamma$ the surface tension, $M$ the molecular weight of the electrolyte, $\rho$ the density of the electrolyte, $r$ the radius of the microdrop, $R$ the gas constant and $T$ the absolute temperature. Cyclic voltammetry with a scanning rate of $50 \mathrm{mV} \mathrm{s}^{-1}$ and a scan range between $0 \mathrm{mV}$ and $500 \mathrm{mV}$ is performed to modulate the surface tension and, therefore, the process of water evaporation. In general, it takes a few cycles to form a well-shaped microcrystal (shown in the insert in Fig. 2). If the electrochemical modulations were not applied, it would take more time for the microcrystal growth to occur. Meanwhile, the shape of the microcrystals would become uncontrollable as reported previously. ${ }^{4}$

Since the lattice size of $\mathrm{Na}_{3} \mathrm{Co}(\mathrm{CN})_{6}(9.39 \AA)$ is very close to that of $\mathrm{NaCl}(9.2 \AA)$, this means that the $\mathrm{Co}(\mathrm{CN})_{6}{ }^{3-}$ units can

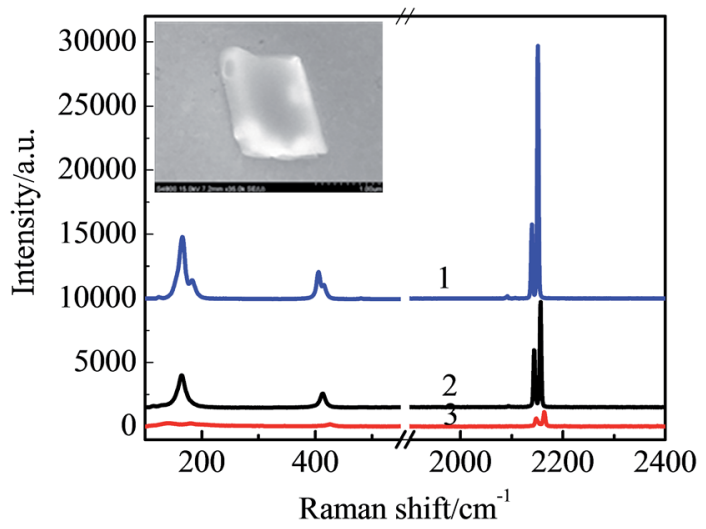

Fig. 2 The confocal Raman spectra of the pure $\mathrm{Na}_{3} \mathrm{Co}(\mathrm{CN})_{6}$ crystals (curve 1), and the single $\mathrm{Na}_{3} \mathrm{Co}(\mathrm{CN})_{6} / \mathrm{NaCl}$ solid solution microcrystals with initial $\mathrm{Na}_{3} \mathrm{Co}(\mathrm{CN})_{6}$ concentration of $10 \mathrm{mM}$ (curve 2) and $1 \mathrm{mM}$ (curve 3); the concentration of the $\mathrm{NaCl}$ in the precursor solution is $50 \mathrm{mM}$. The inset is a SEM image of a single $\mathrm{Na}_{3} \mathrm{Co}(\mathrm{CN})_{6} / \mathrm{NaCl}$ microcrystal. 
take the place of the $\mathrm{NaCl}_{6}{ }^{5-}$ units and dope into the $\mathrm{NaCl}$ microcrystal to form a solid solution. ${ }^{11,12}$ As the valence of the $\mathrm{Co}^{3+}$ is higher than the $\mathrm{Na}^{+}$, to achieve electroneutrality, two $\mathrm{Na}^{+}$ vacancies are left in the neighboring $\mathrm{NaCl}_{6}{ }^{5-}$ units. That means the $\mathrm{Na}_{3} \mathrm{Co}(\mathrm{CN})_{6} / \mathrm{NaCl}$ solid solution is a $\mathrm{Na}^{+}$ionic conductor. Due to the difference between the lattice sizes of the $\mathrm{Na}_{3}-$ $\mathrm{Co}(\mathrm{CN})_{6}$ and the $\mathrm{NaCl}(2.06 \%)$, to some extent, the microcrystals have the characteristics of twin crystals. The crystal defects, including both vacancies and interstitials, are essential to improve the ionic conductivity of the $\mathrm{Na}_{3} \mathrm{Co}(\mathrm{CN})_{6} / \mathrm{NaCl}$ solidsolution microcrystals. ${ }^{13}$ The component of the $\mathrm{Co}(\mathrm{CN})_{6}{ }^{3-}$ in the $\mathrm{NaCl}$ microcrystal is verified by the confocal Raman spectra (Fig. 2). The characteristic bands obtained from the microcrystals are in accordance with that of the pure $\mathrm{Na}_{3} \mathrm{Co}(\mathrm{CN})_{6}$ crystals. The bands at $116 \mathrm{~cm}^{-1}$ and $405 \mathrm{~cm}^{-1}$ are assigned to the $\mathrm{Fe}-\mathrm{C}$ stretching while the bands at $2139 \mathrm{~cm}^{-1}$ and $2151 \mathrm{~cm}^{-1}$ are assigned to the $\mathrm{C} \equiv \mathrm{N}$ stretching. The band strength is relative to the initial concentration of $\mathrm{Na}_{3} \mathrm{Co}(\mathrm{CN})_{6}$ in the precursor solution.

A single $\mathrm{Na}_{3} \mathrm{Co}(\mathrm{CN})_{6} / \mathrm{NaCl}$ microcrystal is assembled into the gap between a pair of gold microwires on a microchip by SECCM to construct an all-in-solid electrochemical system as reported previously (Fig. 1). ${ }^{4}$ Well-defined voltammetric behaviors of $\mathrm{Co}(\mathrm{CN})_{6}{ }^{3-}$ in the $\mathrm{NaCl}$ microcrystal were obtained as shown in Fig. 3. The redox process can be formulated as:

$$
\mathrm{Co}(\mathrm{CN})_{6}^{3-}+\mathrm{e} \rightleftharpoons \mathrm{Co}(\mathrm{CN})_{6}{ }^{4-}
$$

The difference of the peak potentials between the anodic and cathodic processes is rather big $(\sim 450 \mathrm{mV})$, which indicates that the electron transfer reaction is irreversible and kinetically slow. In other words, both the anodic and the cathodic processes need a large overpotential. From the insert of Fig. 3, the peak current has a good linear relationship with the scanning rate. Because the redox units of $\mathrm{Co}(\mathrm{CN})_{6}{ }^{3-}$ are trapped in the lattices of the $\mathrm{NaCl}$ microcrystal, the electron transfer occurs through electron hopping or self-exchange between the neighbouring $\mathrm{Co}(\mathrm{CN})_{6}{ }^{3-}$ units. Meanwhile, to maintain the electroneutrality of the $\mathrm{NaCl}$ microcrystal, the local charges caused by the

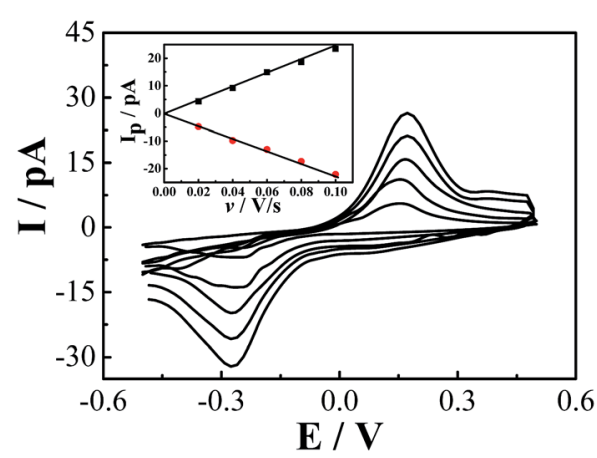

Fig. 3 Cyclic voltammetric behavior of $\mathrm{Co}(\mathrm{CN})_{6}{ }^{3-/ 4-}$ in the $\mathrm{NaCl}$ microcrystals in the dry box. The precursor solution for the culturing of the $\mathrm{NaCl}$ microcrystals contained $10 \mathrm{mM} \mathrm{Co}(\mathrm{CN})_{6}{ }^{3-}$ and $50 \mathrm{mM} \mathrm{NaCl}$. The insert shows the linear relationship between the peak current and the scanning rate. electron transfer are compensated by the diffusion and electromigration of the counterion $\mathrm{Na}^{+}$. Supposing that the electron transfer behavior is similar to the thin-layer voltammetry as analyzed before, the relationship between the peak current and the scanning rate for an irreversible process can be expressed as: $:^{4 a, 4 b, 14}$

$$
i_{\mathrm{p}}=\frac{\alpha n^{2} F^{2} V v C^{*}}{2.718 R T}
$$

where $i_{\mathrm{p}}$ is the peak current, $\alpha$ the charge transfer coefficient, $n$ the stoichiometric charge transfer number, $F$ the Faraday constant, $V$ the volume of the microcrystal, $v$ the scanning rate, $C^{*}$ the bulk concentration of the reactant and $R$ and $T$ are the same as indicated in eqn (1). The dimensions of the single $\mathrm{Na}_{3} \mathrm{Co}(\mathrm{CN})_{6} / \mathrm{NaCl}$ microcrystals are about $2 \mu \mathrm{m} \times 2 \mu \mathrm{m} \times 2 \mu \mathrm{m}$. If $\alpha$ is 0.5 , the apparent concentration of the $\mathrm{Co}(\mathrm{CN})_{6}{ }^{3-}$ in the $\mathrm{NaCl}$ microcrystals can be estimated as $4.3 \times 10^{-5} \mathrm{~mol} \mathrm{~cm}^{-3}$.

Furthermore, electrochemical impedance spectroscopy (EIS) was performed to obtain the kinetic rate of the electron transfer (shown in Fig. 4). Considering that the redox process of $\mathrm{Co}(\mathrm{CN})_{6}{ }^{3-}$ is a simple one-electron transfer reaction as shown in eqn (2), in the range of high frequency, the following equation should be applied: ${ }^{1}$

$$
\left(Z^{\prime}-R_{\mathrm{u}}-R_{\mathrm{et}} / 2\right)^{2}+Z^{\prime \prime 2}=\left(R_{\mathrm{et}} / 2\right)^{2}
$$

where $R_{\mathrm{u}}$ is the Ohm resistance of the single microcrystal, $R_{\mathrm{et}}$ is the electron transfer resistance and $Z^{\prime}$ and $Z^{\prime \prime}$ are the real and imaginary parts of the impedance, respectively. The electron transfer resistance $\left(R_{\mathrm{et}}\right)$ is derived as $1.21 \times 10^{10} \Omega$. By using the geometric parameters and the apparent concentration of the $\mathrm{Co}(\mathrm{CN})_{6}{ }^{3-}$ obtained by cyclic voltammetry, the kinetic rate of the electron transfer, $k_{\mathrm{et}}$, is calculated as $1.24 \times 10^{-5} \mathrm{~cm} \mathrm{~s}^{-1}$. However, Fig. 4 can't provide the mass transfer information, i.e., the diffusion of the counterion $\mathrm{Na}^{+}$in the $\mathrm{NaCl}$ microcrystal. Our previous study shows that the apparent diffusion coefficient $(D)$ of the $\mathrm{Na}^{+}$in the $\mathrm{Na}_{3} \mathrm{Fe}(\mathrm{CN})_{6} / \mathrm{NaCl}$ microcrystals is $8.05 \times 10^{-8} \mathrm{~cm}^{2} \mathrm{~s}^{-1}$. $^{4 b}$ Considering the similarity of the $\mathrm{Na}_{3} \mathrm{Co}(\mathrm{CN})_{6} / \mathrm{NaCl}$ microcrystals, the mass transfer rate, $k_{\mathrm{mt}}$, is estimated as $4.0 \times 10^{-4} \mathrm{~cm} \mathrm{~s}^{-1}$ if the thickness of diffusion layer $(\delta)$ is $2 \mu \mathrm{m}\left(k_{\mathrm{mt}}=D / \delta\right)$. Note that the mass transfer rate is much higher than the electron transfer rate $\left(k_{\mathrm{mt}}>20 k_{\mathrm{et}}\right)$; it can be concluded that the rate-determining step (rds) of the redox reaction of $\mathrm{Co}(\mathrm{CN})_{6}{ }^{3-}$ in the $\mathrm{NaCl}$ microcrystal is the electron propagation in the $\mathrm{NaCl}$ microcrystals. The EIS results elucidate, in turn, the validity of the "irreversible" hypothesis in the discussion section of the cyclic voltammetry.

It should be noted that this reaction can't be observed in conventional solvents even if a mercury electrode is employed to extend the potential window further into the negative. ${ }^{3}$ To elucidate the unique redox behavior of $\mathrm{Co}(\mathrm{CN})_{6}{ }^{3-/ 4-}$ in the $\mathrm{NaCl}$ microcrystal, theoretical calculations were performed using a density functional theory (DFT) method. Fig. 5 gives the potential energy curves (PEC) of the electrochemical reduction process of the $\mathrm{Co}(\mathrm{CN})_{6}{ }^{3-}$ anion in both an aqueous solution $\left(\varepsilon: 78.3 \mathrm{~F} \mathrm{~m}^{-1}\right.$ ) and a $\mathrm{NaCl}$ solid solution $\left(\varepsilon: 6.0 \mathrm{~F} \mathrm{~m}^{-1}\right)$. In aqueous solution, the predicted reorganization energy $\lambda$ is 


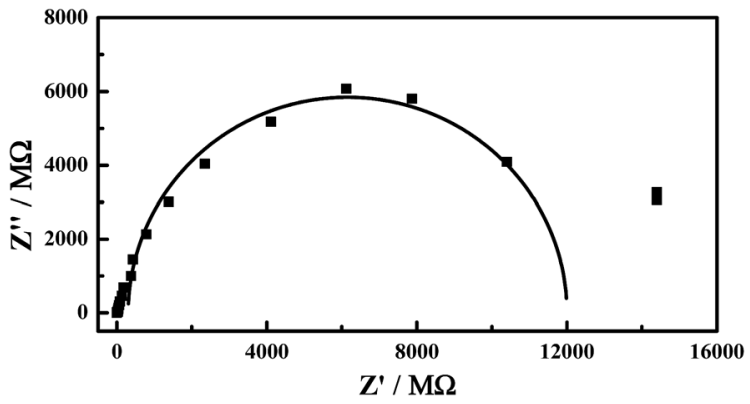

Fig. 4 The electrochemical impedance spectroscopy of the redox couple of $\mathrm{Co}(\mathrm{CN})_{6}{ }^{3-/ 4-}$ in the $\mathrm{NaCl}$ microcrystals. The initial concentration of $\mathrm{Co}(\mathrm{CN})_{6}{ }^{3-}$ for the crystal culture is $10 \mathrm{mM}$.

$2.04 \mathrm{eV}$ after accepting an electron to form the low-spin $\mathrm{Co}(\mathrm{CN})_{6}{ }^{4-}$ anion, which is instable and quickly decomposed into $\mathrm{Co}(\mathrm{CN})_{5}{ }^{3-}$ and $\mathrm{CN}^{\urcorner}$ions by the rupture of the Co-CN bond due to the introduction of an electron. Fig. $5(1 \mathrm{~b})$ gives the corresponding optimization structure, and also the distance between the dissociated $\mathrm{CN}^{\urcorner}$and $\mathrm{Co}(\mathrm{CN})_{5}{ }^{3-}$ anion, which is $10.57 \AA$. It is obvious that there is no bonding interaction between them. However, the high-spin $\mathrm{Co}(\mathrm{CN})_{6}{ }^{4-}$ anion is relatively stable and keeps the original geometric symmetry with a reorganization energy of $1.59 \mathrm{eV}$. It should be noted that the $S_{0}$ and $D_{0}$ PECs have no cross points along the electron transfer reaction coordinate and, if an electron is injected, the relaxation process of the $\mathrm{Co}(\mathrm{CN})_{6}{ }^{3-}$ anion would be irreversible with an enormous stabilization energy of $3.36 \mathrm{eV}$. In summary, in an aqueous solution, the electrochemical reduction product of the $\mathrm{Co}(\mathrm{CN})_{6}{ }^{3-}$ anion prefers to be the low-spin $\mathrm{Co}(\mathrm{CN})_{5}{ }^{3-}$ and the $\mathrm{CN}^{\urcorner}$ion, and the predicted reduction potential is about $-0.98 \mathrm{~V}$ vs. NHE. Unfortunately, in an aqueous solution this redox behavior hasn't been observed experimentally. ${ }^{3}$

However, in the NaCl solid-solution microcrystal, the $S_{0}, D_{0}$ and $\mathrm{Q}_{1} \quad \mathrm{PEC}$ are intersectional. For the reduction of the $\mathrm{Co}(\mathrm{CN})_{6}{ }^{3-}$ anion, the reorganization energy is about $1.54 \mathrm{eV}$. The injected electron just climbs over a low energy barrier

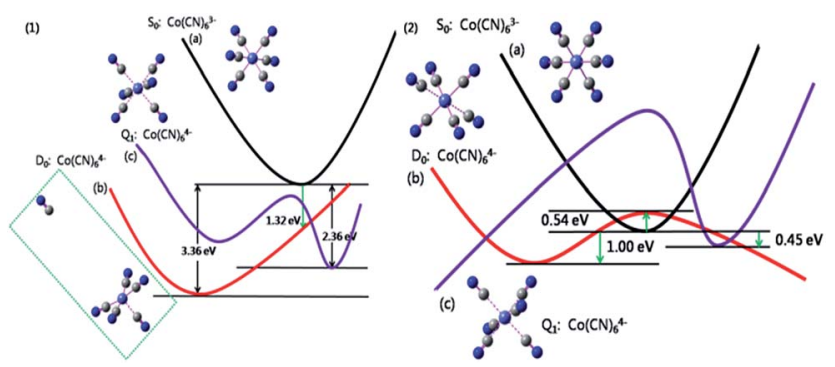

Fig. 5 (1) Qualitative potential energy curves of (a) the $\mathrm{Co}(\mathrm{CN})_{6}{ }^{3-}$ anion $\left(\mathrm{S}_{0}\right.$, black line), (b) the $\mathrm{Co}(\mathrm{CN})_{6}{ }^{4-}$ anion in the low-spin state $\left(\mathrm{D}_{0}\right.$, red line), and (c) the $\mathrm{Co}(\mathrm{CN})_{6}{ }^{4-}$ anion in the high-spin state $\left(\mathrm{Q}_{1}\right.$, purple line) at the PCM-B3LYP/6-311+G**/LANL2DZ level in an aqueous solution $\left(\varepsilon: 78.3 \mathrm{~F} \mathrm{~m}^{-1}\right)$. (2) Potential energy curves of $(a)$ the $\mathrm{Co}(\mathrm{CN})_{6}{ }^{3-}$ anion $\left(\mathrm{S}_{0}\right.$, black line), $(\mathrm{b})$ the $\mathrm{Co}(\mathrm{CN})_{6}{ }^{4-}$ anion in the low-spin state $\left(\mathrm{D}_{0}\right.$, red line), and (c) the $\mathrm{Co}(\mathrm{CN})_{6}{ }^{4-}$ anion in the high-spin state $\left(Q_{1}\right.$, purple line) at the PCM-B3LYP/6-311+G**/LANL2DZ level in a $\mathrm{NaCl}$ solid solution $\left(\varepsilon: 6.0 \mathrm{~F} \mathrm{~m}^{-1}\right)$.
$(<0.54 \mathrm{eV})$ to enter the $\mathrm{D}_{0}$ PEC and relaxes into the product, the low-spin $\mathrm{Co}(\mathrm{CN})_{6}{ }^{4-}$ anion, which is stabilized and keeps the original coordination number in the dielectric environment of the NaCl microcrystal. Meanwhile, the oxidation energy barrier of the reverse process is just between 1.00 and $1.54 \mathrm{eV}$. The low dielectric constant $\left(\varepsilon: 6.0 \mathrm{~F} \mathrm{~m}^{-1}\right)$ leads to a smaller stabilization energy of $1.00 \mathrm{eV}$ and, consequently, an electrochemical redox process of the $\mathrm{Co}(\mathrm{CN})_{6}{ }^{3-/ 4-}$ couple. It can be concluded that the dielectric environment plays a vital role in not only the thermodynamic possibility but also the electrode kinetics of the electron transfer processes. The $\mathrm{NaCl}$ solid-solution microcrystal can provide a suitable dielectric environment for the hexacyanides of transition metals which are expected to have good electron transfer properties but, for some reason, aren't present in the conventional electrolyte solutions at ambient temperature.

\section{Conclusions}

For the first time, we obtained the well-defined redox behavior of $\mathrm{Co}(\mathrm{CN})_{6}{ }^{3-/ 4-}$ in single $\mathrm{NaCl}$ microcrystals. The formation mechanism of the $\mathrm{Co}(\mathrm{CN})_{6}{ }^{3-} / \mathrm{NaCl}$ solid solution is confirmed by both crystallographic principles and a confocal Raman spectra experiment. The electrochemical investigations show that the electrode process is kinetically controlled, which is elucidated in the DFT calculations. DFT results show that the reactant, $\mathrm{Co}(\mathrm{CN})_{6}{ }^{4-}$, is stabilized and the active energy of the redox couple, $\mathrm{Co}(\mathrm{CN})_{6}{ }^{3-/ 4-}$, is lowered in the special dielectric environment of the $\mathrm{NaCl}$ microcrystals. This dielectric-dependent electron transfer behavior recalls the crucial role of the dielectric environment of the electrochemical system. A proper dielectric environment can present the electron transfer behavior expected in theory, but hardly ever obtained in experiments. Moreover, the $\mathrm{NaCl}$ solid solution is proved as a prospective solvent for solid-state electrochemistry in ambient temperature, which might have potential application in all-insolid sensors or power sources.

\section{Acknowledgements}

Huang, Zhu and Su have equal contributions. The financial supports by the National Science Foundation of China (No. 21327002, 91323303, and 21321062), NFFTBS (No. J1310024), the Natural Science Foundation of Fujian Province of China (No. 2012J06004), and Program for New Century Excellent Talents in University (NCET-12-0318) are appreciated.

\section{References}

1 A. J. Bard and L. R. Faulkner, Electrochemical Methods: Fundamentals and Methods, John Wiley \& Sons, New York, 2nd edn, 2001.

2 S. Dong, G. Che and Y. Xie, Chemical Modified Electrode, Science Press, Beijing, 2nd edn, 2003.

3 V. Y. Kotov, R. R. Nazmutdinov, G. N. Botukhova, G. A. Tsirlina and O. A. Petrii, Hard-to-detect Co III/Co II 
reduction in a hexacyanocobaltate, Mendeleev Commun., 2004, 14, 113-115.

4 (a) D. Yang, L. Han, Y. Yang, L. B. Zhao, C. Zong, Y. F. Huang, D. Zhan and Z. Q. Tian, Solid-State Redox Solutions: Microfabrication and Electrochemistry, Angew. Chem., Int. Ed., 2011, 123, 8838-8841; (b) D. Zhan, D. Yang, B.-S. Yin, J. Zhang and Z.-Q. Tian, Electrochemical Behaviors of Single Microcrystals of Iron Hexacyanides/NaCl Solid Solution, Anal. Chem., 2012, 84, 9276-9281; (c) D. Zhan, D. Yang, Y. Zhu, X. Wu and Z.-Q. Tian, Fabrication and characterization of nanostructured $\mathrm{ZnO}$ thin film microdevices by scanning electrochemical cell microscopy, Chem. Commun., 2012, 48, 11449-11451.

5 (a) A. Hassel and M. Lohrengel, The scanning droplet cell and its application to structured nanometer oxide films on aluminium, Electrochim. Acta, 1997, 42, 3327-3333; (b) M. Lohrengel, A. Moehring and M. Pilaski, Capillary-based droplet cells: limits and new aspects, Electrochim. Acta, 2001, 47, 137-141; (c) T. W. Spaine and J. E. Baur, A Positionable Microcell for Electrochemistry and Scanning Electrochemical Microscopy in Subnanoliter Volumes, Anal. Chem., 2001, 73, 930-938; (d) K. T. Rodolfa, A. Bruckbauer, D. Zhou, Y. E. Korchev and D. Klenerman, Two-Component Graded Deposition of Biomolecules with a Double-Barreled Nanopipette, Angew. Chem., Int. Ed., 2005, 117, 7014-7019; (e) N. Ebejer, M. Schnippering, A. W. Colburn, M. A. Edwards and P. R. Unwin, Localized High Resolution Electrochemistry and Multifunctional Imaging: Scanning Electrochemical Cell Microscopy, Anal. Chem., 2010, 82, 9141-9145; ( $f$ ) J. Hu and M.-F. Yu, Meniscus-Confined Three-Dimensional Electrodeposition for Direct Writing of Wire Bonds, Science, 2010, 329, 313316.

6 (a) S. Lai, A. N. Patel, K. McKelvey and P. R. Unwin, Definitive Evidence for Fast Electron Transfer at Pristine Basal Plane Graphite from High-Resolution Electrochemical Imaging, Angew. Chem., Int. Ed., 2012, 124, 5501-5504; (b) A. N. Patel, M. G. Collignon, M. A. O'Connell, W. O. Hung, K. McKelvey, J. V. Macpherson and P. R. Unwin, A New View of Electrochemistry at Highly Oriented Pyrolytic Graphite, J. Am. Chem. Soc., 2012, 134, 20117-20130; (c) A. G. Güell, N. Ebejer, M. E. Snowden, J. V. Macpherson and P. R. Unwin, Structural Correlations in Heterogeneous Electron Transfer at Monolayer and Multilayer Graphene Electrodes, J. Am. Chem. Soc., 2012, 134, 7258-7261.

7 (a) H. V. Patten, S. C. Lai, J. V. Macpherson and P. R. Unwin, Active Sites for Outer-Sphere, Inner-Sphere, and Complex Multistage Electrochemical Reactions at Polycrystalline Boron-Doped Diamond Electrodes (pBDD) Revealed with Scanning Electrochemical Cell Microscopy (SECCM), Anal. Chem., 2012, 84, 5427-5432; (b) A. N. Patel, K. McKelvey and P. R. Unwin, Nanoscale Electrochemical Patterning Reveals the Active Sites for Catechol Oxidation at Graphite Surfaces, J. Am. Chem. Soc., 2012, 134, 20246-20249.

8 (a) S. O. Klemm, J. P. Kollender and A. Walter Hassel, Combinatorial corrosion study of the passivation of aluminium copper alloys, Corros. Sci., 2011, 53, 1-6; (b)
A. I. Mardare, A. Ludwig, A. Savan, A. D. Wieck and A. W. Hassel, Combinatorial investigation of Hf-Ta thin films and their anodic oxides, Electrochim. Acta, 2010, 55, 7884-7891; (c) K. Fushimi, S. Yamamoto, R. Ozaki and H. Habazaki, Cross-section corrosion-potential profiles of aluminum-alloy brazing sheets observed by the flowing electrolyte scanning-droplet-cell technique, Electrochim. Acta, 2008, 53, 2529-2537.

9 (a) A. O. Okunola, T. C. Nagaiah, X. Chen, K. Eckhard, W. Schuhmann and M. Bron, Visualization of local electrocatalytic activity of metalloporphyrins towards oxygen reduction by means of redox competition scanning electrochemical microscopy (RC-SECM), Electrochim. Acta, 2009, 54, 4971-4978; (b) X. Chen, K. Eckhard, M. Zhou, M. Bron and W. Schuhmann, Electrocatalytic Activity of Spots of Electrodeposited Noble-Metal Catalysts on Carbon Nanotubes Modified Glassy Carbon, Anal. Chem., 2009, 81, 7597-7603; (c) S. C. Lai, P. V. Dudin, J. V. Macpherson and P. R. Unwin, Visualizing Zeptomole (Electro)Catalysis at Single Nanoparticles within an Ensemble, J. Am. Chem. Soc., 2011, 133, 10744-10747.

10 (a) L. Fisher and J. Israelachvili, Direct experimental verification of the Kelvin equation for capillary condensation, Nature, 1979, 277, 548-549; (b) L. R. Fisher and J. N. Israelachvili, Experimental studies on the applicability of the Kelvin equation to highly curved concave menisci, J. Colloid Interface Sci., 1981, 80, 528-541.

11 D. J. Carter, M. I. Ogden and A. L. Rohl, Incorporation of Cyano Transition Metal Complexes in $\mathrm{KCl}$ CrystalsExperimental and Computational Studies, Aust. J. Chem., 2003, 56, 675-678.

12 (a) K. Itaya, I. Uchida and V. D. Neff, Electrochemistry of polynuclear transition metal cyanides: Prussian blue and its analogues, Acc. Chem. Res., 1986, 19, 162-168; (b) P. V. Sushko, A. L. Shluger, R. C. Baetzold and C. R. Catlow, Embedded cluster calculations of metal complex impurity defects: properties of the iron cyanide in $\mathrm{NaCl}$, J. Phys.: Condens. Matter, 2000, 12, 8257.

13 P. J. Gellings and H. J. M. Bouwmeester, The CRC Handbook of Solid State Electrochemistry, CRC Press, New York, 1997.

14 R. S. Tyurin, Y. S. Lyalikov and S. I. Zhdanov, Thin-Layer Electrochemistry, Russ. Chem. Rev., 1972, 41, 1086-1100.

15 (a) D. Zhan, S. Mao, Q. Zhao, Z. Chen, H. Hu, P. Jing, M. Zhang, Z. Zhu and Y. Shao, Electrochemical Investigation of Dopamine at the Water/1,2-Dichloroethane Interface, Anal. Chem., 2004, 76, 4128-4136; (b) D. Zhan, X. Li, W. Zhan, F.-R. F. Fan and A. J. Bard, Scanning Electrochemical Microscopy. 58. Application of a Micropipet-Supported ITIES Tip To Detect $\mathrm{Ag}+$ and Study Its Effect on Fibroblast Cells, Anal. Chem., 2007, 79, 52255231; (c) D. Zhan, F.-R. F. Fan and A. J. Bard, The Kv channel blocker 4-aminopyridine enhances Ag+ uptake: A scanning electrochemical microscopy study of single living cells, Proc. Natl. Acad. Sci. U. S. A., 2008, 105, 12118-12122; (d) W. Wang, J. Zhang, L. Han, D. Yang and D. Zhan, Generation/collection mode of SECM with combined probe, Chin. Chem. Lett., 2012, 23, 86-88; (e) G. Girma, 
L.-J. Yu, L. Huang, S. Jin, D.-Y. Wu and D. Zhan, Anal. Methods, 2013, 5, 4666-4670; (f) U. Nestor, H. Wen, G. Girma, Z. Mei, W. Fei, Y. Yang, C. Zhang and D. Zhan, Facilitated $\mathrm{Li}+$ ion transfer across thewater/1,2dichloroethane interface by the solvation effect, Chem. Commun., 2014, 50, 1015-1017.

16 (a) C. Lee, W. Yang and R. G. Parr, Development of the ColleSalvetti correlation-energy formula into a functional of the electron density, Phys. Rev. B: Condens. Matter Mater. Phys., 1988, 37, 785; (b) A. D. Becke, Density-functional thermochemistry. III. The role of exact exchange, J. Chem. Phys., 1993, 98, 5648-5652; (c) M. Frisch, G. Trucks, H. B. Schlegel, G. Scuseria, M. Robb, J. Cheeseman, G. Scalmani, V. Barone, B. Mennucci and G. Petersson, Gaussian 09, Revision A. 02, Gaussian. Inc., Wallingford, CT, 2009.

17 (a) R. Krishnan, J. S. Binkley, R. Seeger and J. A. Pople, Selfconsistent molecular orbital methods. XX. A basis set for correlated wave functions, J. Chem. Phys., 1980, 72, 650654; (b) A. McLean and G. Chandler, Contracted Gaussian basis sets for molecular calculations. I. Second row atoms, $Z=11-18$, J. Chem. Phys., 1980, 72, 5639-5648.

18 (a) P. J. Hay and W. R. Wadt, Ab initio effective core potentials for molecular calculations. Potentials for the transition metal atoms Sc to Hg, J. Chem. Phys., 1985, 82, 270-283; (b) W. R. Wadt and P. J. Hay, $A b$ initio effective core potentials for molecular calculations: Potentials for main group elements Na to Bi, J. Chem. Phys., 1985, 82, 284-298.

19 (a) E. Cances, B. Mennucci and J. Tomasi, A new integral equation formalism for the polarizable continuum model: theoretical background and applications to isotropic and anisotropic dielectrics, J. Chem. Phys., 1997, 107, 30323041; (b) M. Cossi, V. Barone, B. Mennucci and J. Tomasi, $A b$ initio study of ionic solutions by a polarizable continuum dielectric model, Chem. Phys. Lett., 1998, 286, 253-260. 